\title{
Validity of the correlation of gallstones and pancreatic pathology
}

\author{
W. F. ERBER, E. LUBOWSKI, I. S. LEVIJ, AND D. BIRNBAUM \\ From the Gastroenterological Service and the Department of Pathology, Hebrew University-Hadassah \\ Medical School, Jerusalem, Israel
}

SUMMARY In a necropsy survey of 724 patients from the Hebrew University Hospital (1964-67) 107 patients were found with gallstones. Ninety-five patients matched according to age and sex served as controls.

No difference was found between control and gallstone patients with regard to the incidence and type of pancreatic pathology, except for intestinal metaplasia which was more frequent in the controls.

Significantly more pancreatic pathology was found in Ashkenazi-born patients without gallstones than in the respective non-Ashkenazi group. In patients with gallstones no difference in pancreatic pathology was found between the two ethnic groups.

Females with gallstones had significantly more hepatic disease than females without gallstones. This difference was not found in males.

Hepatic disease alone was associated with a higher incidence of pancreatic pathology.

Much has been written in the medical literature on the association of gallbladder disease, specifically gallstones, and pancreatic inflammation. However, when attempting to analyze the correlation between these two entities, it becomes apparent that in most instances they were not statistically tested or verified against control populations. Another source of confusion is the lack of uniform histological criteria for defining significant pancreatic pathology. For example, the percentage of incidental interstitial pancreatitis found in adult necropsies varies from 0.13 to $66 \%$ (Czernobilsky and Mikat, 1964). It has been stated in the literature that the two clinical entities most commonly contributing to pancreatic inflammation are gallstones and alcoholism (Phillips, 1954; Bockus, 1965; White, 1966; O'Sullivan, Nobrega, Morlock, Brown, and Bartholomew, 1972). In Israel, the problem of alcoholism is a negligible one. With the improvement of the longevity of man, an increasing incidence of gallstones and its associated complications may be expected. It is very important for the physician to know which coexistent and complicating diseases he must be prepared to deal with. Is there a relationship between gallstones and pancreatic pathology or are the associations so frequently discussed merely fortuitious?

Received for publication 4 October 1972.
This question can only be answered in a critically analyzed study.

\section{Methods}

This study is based on 724 necropsies performed at the Hadassah University Hospital in Jerusalem during the years 1964-67. In 107 patients gallstones were found. The data were analyzed according to sex and age distribution. Only 95 patients without gallstones, taken from the same years, were available as matched controls. Since only seven patients below the age of 40 years were found, they were not included in the statistical evaluation of our data. Our final gallstone and control groups were 103 and 92 cases respectively, a total of 195 cases.

The pancreatic sections of all the patients were reviewed in detail. The specific histopathological findings which were looked for and considered by us as important were as follows: intestinal metaplasia of duct epithelium (Rich and Duff, 1936; Walters, 1965); acute pancreatitis, moderate to marked diffuse acute inflammation and necrosis; chronic pancreatitis, moderate to marked focal and diffuse chronic inflammation. Interstitial fibrosis, focal and diffuse, was considered significant if it was moderate to marked; and carcinoma, primary or metastatic. It was impossible to evaluate the extent of the lesions 
throughout the pancreas because only two to five routine sections were available in each case, so some focal lesions may have been missed in the control and gallstone group. The sections were reviewed by all of us independently and not knowing which sections were from the control or gallstone population. The discrepancies in interpretation of the sections were minimal. The final interpretation was made by the pathologist.

The postmortem reports of all the patients (103 gallstone and 92 control) were reviewed and the following specific points were looked for: hepatic disease (primary and metastatic tumours, inflammation, chronic persistent hepatitis, cholestasis, liver infarcts, haemangioma, haemosiderosis, haemochromatosis and cirrhosis); biliary tract disease (inflammation, stones); duodenal ulcer; surgical procedures in the region of the pancreas and in remote areas in the past.

The clinical records of 127 out of 195 patients that were available for review were analyzed for (1) ethnic affiliation, Ashkenazi (European- and American-born patients) and non-Ashkenazi (African- and Asian-born patients); (2) diabetes (the diagnosis of diabetes was based on repeated findings of fasting blood sugar levels above $140 \mathrm{mg} \%$ and glycosuria); (3) alcoholism; (4) whether or not the diagnosis of pancreatitis was ever made clinically.

In the statistical evaluations the $\chi^{2}$ test was applied.

\section{Results}

Our study included a total of 195 necropsies, 92 controls and 103 patients with cholelithiasis. In nine out of these 103 patients choledocholithiasis was found and in 11 cholecystectomy was performed in the past.

The female: male ratio in the control group was 1.37 and 1.20 in the gallstone population. The ratio in the controls with pathology of the pancreas was 1.93 while in the gallstone population with pancreatic pathology it was 0.96 .

No significant difference was found between the control population and the gallstone patients with regard to the incidence of pancreatic pathology in females and males. In the female controls, 27 out of a total of $53(50.9 \%)$ patients had pathology of the pancreas compared with 24 out of $56(42.8 \%)$ in the female gallstone group. In male controls, 14 out of 39 patients $(35.8 \%)$ had pancreatic pathology compared with 25 out of $47(53.2 \%)$ male gallstone patients $(P>0.05)$.

The types of significant pathology of the pancreas are summarized in Table I. Control and gallstone patients show a similar distribution, except for intestinal metaplasia, which was found in a signifi-

\begin{tabular}{|c|c|c|c|c|}
\hline \multirow[t]{2}{*}{ Pathology } & \multicolumn{2}{|c|}{ Control } & \multicolumn{2}{|c|}{ Gallstones } \\
\hline & $\begin{array}{l}\text { No. of } \\
\text { Males }\end{array}$ & $\begin{array}{l}\text { No. of } \\
\text { Females }\end{array}$ & $\begin{array}{l}\text { No. of } \\
\text { Males }\end{array}$ & $\begin{array}{l}\text { No. of } \\
\text { Females }\end{array}$ \\
\hline Intestinal metaplasia & 10 & 17 & 11 & 11 \\
\hline Acute pancreatitis & 3 & 1 & 4 & 6 \\
\hline Chronic pancreatitis & 0 & 7 & 4 & 4 \\
\hline Interstitial fibrosis & 8 & 8 & 15 & 11 \\
\hline Tumours & 2 & 3 & 3 & 3 \\
\hline $\begin{array}{l}\text { Total number of patients with } \\
\text { pathology of the pancreas } \\
\text { Total number of necropsies }\end{array}$ & $\begin{array}{l}14 \\
39\end{array}$ & $\begin{array}{l}27 \\
53\end{array}$ & $\begin{array}{l}25 \\
47\end{array}$ & $\begin{array}{l}24 \\
56\end{array}$ \\
\hline
\end{tabular}

Table I Types of pancreatic pathology

cantly higher percentage in the control group (27 out of 41 ) as compared to the gallstone group (21 out of 49, $P<0.05$ ). However, when this finding was correlated to the total necropsy population, 27 out of 92 controls and 21 out of 103 gallstone patients, no significant difference was found between the two groups.

In patients without gallstones, significantly more pancreatic pathology was found in Ashkenazi patients, namely, 26 out of $46(56.5 \%)$ as compared to that in non-Ashkenazi patients, three out of 17 $(17.6 \%)\left(\chi^{2}=6.07, P<0.02\right)$. In patients with gallstones, no significant difference in pancreatic pathology between these two ethnic groups was found.

Hepatic disease was found in $\mathbf{5 2}$ out of 92 controls and in 79 out of 103 gallstone patients. The female: male ratio in the controls with hepatic disease was 1.6 and in the gallstone population with hepatic disease it was 1.63. In control patients with hepatic disease there was a significantly higher incidence of pathology of the pancreas, namely, 29 out of 52 $(55.7 \%)$ than in the control group without hepatic disease in which it was 12 out of $40(30 \%)\left(\chi^{2}=\right.$ $5.08, P<0.05)$. Pancreatic pathology in patients with gallstones did not differ significantly in those with or without hepatic disease (46.8 and $50 \%$ respectively).

Females with gallstones had significantly more hepatic disease than those without gallstones (49 out of 56 and 32 out of 53), $\chi^{2}=9.12, P<0.01$ ). In males with gallstones, the incidence of hepatic disease was not significantly higher than in those without gallstones (30 out of 47 and 20 out of 39 respectively).

Duodenal ulcer was found to be more frequent in patients with gallstones in 15 out of $103(14.5 \%)$ as compared to those without gallstones, namely, eight out of $92(8.7 \%)$. Pancreatic pathology in duodenal ulcer patients was found in two out of eight patients in the control group and in five out of 15 patients in the gallstone group.

Thirty-one patients in the control group and 41 
patients in the gallstone group underwent surgery in the past. Ten patients in the control group and 22 in the gallstone group had surgery in the area of the pancreas. Pancreatic pathology was found in seven of the control patients $(70 \%)$ and in 13 of the gallstone patients $(59 \%)$. In surgical procedures in an area remote from the region of the pancreas, 11 out of 21 patients $(52 \%)$ in the control group and six out of 19 patients $(32 \%)$ in the gallstone group had pancreatic pathology.

In 127 clinical records reviewed, there were 40 patients with diabetes (blood sugar level from 142 to $714 \mathrm{mg} \%$, average $249 \mathrm{mg} \%$ ), 85 without diabetes and two patients where the diagnosis was not certain. Gallstone patients with diabetes did not have a higher incidence of pancreatic pathology as compared to diabetic patients without stones (seven out of $16(43.7 \%)$ and 12 out of $24(50 \%)$ respectively).

Alcoholism was found in two patients only.

Clinical suspicion of pancreatic disease was raised in only four out of the 127 patients.

\section{Comment}

The correlation of gallstones and pancreatic disease is based on studies of acute, chronic, and fatal pancreatitis in clinical and necropsy surveys. In most of the studies no comparison with a matched control population of patients without gallstones was made.

In studies (Lieber, 1952; Sjöberg, 1953; Thal, Perry, and Egner, 1957; Bell, 1958; Whalen, Rush, Albano, and Lazaro, 1971) which included a total of 2196 cases with acute pancreatitis gallstones were found in 1285 of them (58.5\%) ranging from 40.9 to $66.7 \%$. In necropsy data, based on 2559 consecutive necropsies, $12 \%$ of the total necropsy population showed chronic cholecystitis with cholelithiasis as compared with $15.7 \%$ in patients with acute pancreatitis. These data do not support the generally accepted idea that the incidence of gallstones is significantly higher in acute pancreatitis than in the general population (Joshi, Probstein, and Blumenthal, 1957). In a review of the English literature, 635 cases with relapsing pancreatitis were reported, 230 of them were found with cholelithiasis $(36.2 \%)$ and $52(8.2 \%)$ had common duct stones (Howard and Jordan, 1956). The histopathological features of pancreatic disease in patients with chronic relapsing pancreatitis, with or without biliary tract disease, were reported to be essentially the same (Gambill, Comfort, and Baggenstoss, 1948). In a study based on 279 necropsies, in which an average of two pancreatic sections per case were examined, interstitial pancreatitis was diagnosed in 43 cases (15\%). Cholelithiasis was found in $20.9 \%$ of patients with interstitial pancreatitis compared to $16.9 \%$ in the control group (Czernobilsky and Mikat, 1964).

The incidence of pancreatic pathology in patients with cholelithiasis varies from 0.62 to $7.6 \%$ (Lieber, 1952; Bell, 1958; Kozoll, Dwyer, and Meyer, 1959). In controls without gallstones the incidence of pancreatic pathology ranges from 0.162 to $1 \cdot 17 \%$ (Lieber, 1952; Bell, 1958). In 146 cases of choledocholithiasis pancreatic involvement was found in $21.8 \%$. In cholecystitis without stones seven out of 55 patients had pancreatic pathology (Kozoll et al, 1959). Our survey reveals pancreatic pathology in 49 out of 103 patients with cholelithiasis, including five out of nine patients with choledocholithiasis. The respective figures in the control population were 41 and 92. Thus, we did not find a significant difference between the two matched groups.

In patients without gallstones we found a significantly lower incidence of pancreatic pathology in non-Ashkenazi than in Ashkenazi patients. While investigating other associated diseases, hepatic disease was found to be more frequent in the Ashkenazi group (66 and 50\%); however this difference was not statistically significant. In patients with gallstones no significant difference in the incidence of pancreatic pathology was found between the two ethnic groups, a finding which may suggest that gallstones in non-Ashkenazi people favour the development of pancreatic pathology. Lieber (1952) reported a difference in the incidence of pancreatic pathology in white and negro patients. Negro patients without gallstones have a higher incidence of pancreatic pathology than white patients without gallstones $(0.375$ and $0.162 \%)$. In gallstone patients the incidence of pancreatic pathology was 0.88 and $1.32 \%$ respectively.

The higher incidence of hepatic disease found in females with gallstones $(87.5 \%)$ compared with those without gallstones $(60 \%)$ may imply that hepatic disease is causally related to gallstones or vice versa. This confirms reports of Kozoll et al (1959) and Newman and Northup (1959) who found a higher incidence of hepatic disease in patients with gallstones.

Pancreatic pathology was found to be significantly lower in the control group without hepatic disease compared with those with hepatic disease. In patients with gallstones the incidence of pancreatic pathology did not differ in those with or without hepatic disease. Thus one may assume that hepatic disease is as important as gallstones in the aetiology of pancreatic pathology.

One type of pancreatic pathology, namely, metaplasia, is as yet controversial. Metaplasia of the epithelium of the pancreatic ducts usually involved medium-sized ducts and in rare instances also smaller 
ducts (Henke and Lubarsch, 1929; Rich and Duff, 1936). The metaplastic areas usually contained groups of goblet cells as normally seen in the intestinal mucosa. Less frequently another type of metaplasia was noted, where island of non-keratinizing squamous epithelium were present in the duct mucosa. Goblet cells or intestinal metaplasia have been noted frequently and some authors regard it as a physiological phenomenom (Henke and Lubarsch, 1929; Robbins, 1967). However, Rich and Duff (1936) and Walters (1965), regarded both goblet cells and squamous metaplasia as abnormalities, usually related to atrophic parts of the exocrine pancreas showing interstitial fibrosis. The aetiology of metaplasia is unknown. It has been suggested to be a result of chronic inflammatory changes. Others asserted that this type of metaplasia is primary causing obstruction of pancreatic ducts with stasis of secretion, leading to atrophy and fibrosis and possibly to acute haemorrhagic pancreatitis (Rich and Duff, 1936). We regarded metaplasia of the pancreatic duct epithelium as an abnormal finding, although it is uncertain whether this lesion is the cause or the result of pancreatic pathology.

Our findings with regard to surgery confirm reports of Boles (1956) and Brown (1954) that in the area of the pancreas surgery may be associated with a higher degree of pancreatic pathology than when remote from the pancreas.

The purpose of our study was to examine whether there is a significant difference in the incidence of pancreatic pathology in patients with and without gallstones, matched according to age and sex. Since no significant difference was found between these two groups, the repeated statements on the predominant correlation of pancreatic pathology to gallstones is questioned and other associated diseases or aetiological factors will have to be more carefully investigated.
References

Bell, E. T. (1958). Pancreatitis. Surgery, 43, 527-537.

Bockus, H. L. (1965). Gastroenterology, 2nd ed., Vol. III, p. 955. Saunders, Philadelphia.

Boles, E. T., Jr. (1956). Postoperative pancreatitis. Arch. Surg., 73, $710-718$.

Brown, M. J. (1954). Pancreatic fatalities of biliary tract operations. Amer. J. Surg., 88, 261-265.

Czernobilsky, B., and Mikat, K. W. (1964). The diagnostic significance of interstitial pancreatitis found at autopsy. Amer. J. clin. Path., 41, 33-43.

Gambill, E. E., Comfort, M. W., and Baggenstoss, A. H. (1948) Chronic relapsing pancreatitis: an analysis of 27 cases associated with disease of the biliary tract. Gastroenterology, 11 1-33.

Henke, F., and Lubarsch, O., Eds. (1929). Handbuch der speziellen pathologischen Anatomie und Histologie, Band V/2. Springer, Berlin.

Howard, J. M., and Jordan, G. L., Jr. (1956). Relapsing pancreatitis secondary to choledocholithiasis. Arch. Surg., 73, 960-964.

Kozoll, D. D., Dwyer, G., and Meyer, K. A. (1959). Pathologic correlation of gallstones. Arch. Surg., 79, 514-536.

Joshi, R. A., Probstein, J. G., and Blumenthal, H. T. (1957). A survey of experiences with 300 clinical and 108 autopsy cases of acute pancreatitis. Amer. Surg., 23, 34-42.

Lieber, M. M. (1952). The incidence of gallstones and their correlation with other diseases Ann Surg., 135, 394-465.

Newman, H. F., and Northup, J. D. (1959). The autopsy incidence of gallstones. Int. Abstr. Surg., 109, 1-13.

Phillips, A. M. (1954). Chronic pancreatitis-pathogenesis and clinica features: a study of 28 cases. Arch. intern. Med., 93, 337-354.

Rich, A. R., and Duff, G. L. (1936). Experimental and pathological studies on the pathogenesis of acute haemorrhagic pancreatitis. Bull. Johns Hopk. Hosp., 58, 212.

Robbins, S. L. (1967). Pathology. Saunders, Philadelphia.

Sjöberg, S. G. (1953). The role of diseases of the liver and the biliary tracts in the development of pancreatitis. Gastroenterologia (Basel), 80, 263.

O’Sullivan, J. N., Nobrega, F. T., Morlock, C. G., Brown, A. L. Jr., and Bartholomew, L. G. (1972). Acute and chronic pancreatitis in Rochester, Minnesota. 1940 to 1969. Gastroenterology, 62, 373-379.

Thal, A. P., Perry, J. F., Jr., and Willadene, E. (1957). A clinical and morphological study of forty-two cases of fatal acute pancreatitis. Surg. Gynec. Obstet., 105, 191-202.

Walters, M., N-I. (1965). Goblet cell metaplasia in ductules and acini of the exocrine pancreas. J. Path. Bact., 89, 569-572.

Whalen, J., Rush, B., Albano, E., and Lazaro, E. (1971). Fatal acute pancreatitis, a clinicopathologic analysis Amer. J. Surg., 121, 16-19.

White, T. T. (1966). Pancreatitis. Arnold, London. 